\title{
THE ENDOSCOPIC GAZE: Objectivity and Objectification Go Inside the Body (and Out Again)
}

By Robyn Fadden

ndoscopy is a medical technique used for exploratory or surgical
purposes, wherein a small camera-like device attached to the end of a probe is inserted into the body through a natural orifice or an incision if necessary. In the past, starting as early as the beginning of the 19th century, the endoscope was just that, a scope, and the physicians were the only ones who saw what it showed. However, in the past 20 years, a digital camera has been added to the scope, allowing surgeons to operate not only by looking directly into the scope but at a television-like monitor as well. Often the patient is able to view the exploration of his or her own body on this screen or might see a recording after surgery. With this evolution in the technology to include the creation of images or representations of the body, endoscopy's impact transcended the medical field to become a form of media, a way of representing the world of the body and the body in the world. José Van Dijck points out that further explorations of endoscopic technology increased when the media disseminated video images of the inside of the body, sparking the interest of the general public. This interest only grows as endoscopic technologies continue to advance and theirsociocultural impacts continue to develop.

My main reason for undertaking this research is to explore the links between medical technologies, specifically technologies that have a visual culture component, and how the human body is understood through the perceived distance of media. My inquiry is not about what is and is not real or true, but about the communication of information and the reconciliation of new information with what is already known about one's own body through the discourses of science, medicine and the media. My main research question here 
asks: What are the repercussions, effects, and outcomes of medical technologies such as endoscopy when the images they produce become a part of the broader cultural context - a context that alters as soon as those images come into being? What becomes of the body, not only in medicine, but in the varying ontological understandings of our own bodies as living systems and as ourselves? This technology could be understood as another way of seeing and trying to understand something - still based on our own eye, but able to go places our eye cannot. To better understand this, we must further examine the technologies and their cultural-historical context, as well as the images produced and how those images are interpreted.

The biological body has been revealed to us throughout history; through artists' drawing of models, detailed medical drawings of cadavers, or digital endoscopic images, its surfaces have been rendered in the pursuit of information and knowledge, so that we might better understand the role our bodies play in our lives. Yet always our vision is mediated - the body is beyond another lens. How much control do we have over this mediation? Are the lenses we have created more a part of ourselves than we know or admit? After all, film was created based on our own eye and is often thought to afford us a level of objectivity better than our own eye can manage. How close to "objective" must this technological eye be deemed and with what criteria do we designate it so? Is this a question of science, art or culture? At this point in history, it is neglectful of us not to say all three.

José Van Dijck compares the "endoscopic gaze" that makes the invisible visible with Laura Mulvey's "cinematic gaze," writing that the "endoscopic gaze signifies the surgeon's view from within the body, enabled by medical technology" (221). Due to the surgeon's gaze and endoscopic images of the inside of the body, our perspective of the body now includes both the external and interior, both of which have been mediated to us through the images of media technologies. What do we then do with these images? They are a form of information brought to us through a film-like medical 
media technology and interpreted for us by medical professionals entrenched in their discourse. Yet we view them in many different contexts, such as the doctor's office, television or the web, which add more complexity to our interpretations. History and the sociocultural do not just surround technologies or create them but are also created through them.

\section{Technologies in culture, culture in technologies}

In this research, technology is understood as contributing to sociocultural change in a particular way. It is a part of culture and the discourses that influence our observations and interpretations, tapping into what we already know so that we may build metaphors and narratives around it. Technology here goes beyond the instrumental, understood more along the lines of Heidegger's "essence" and therefore as a part of being and understanding the world - it is part of the spaces we exist and connect in. Analyzing technologies allows us to discover the complex sets of meanings that are linked to the technologies' purposes and intended and unintended uses. In Ursula Franklin's The Real World of Technology, technology is understood as a practice, a system of interactions, or an organization of work and people, procedures, symbols and mindsets. Technology changes the nature of our experience and acts as an agent of power and control - it can define content and vice-versa. Franklin writes: "Technologies are developed and used within a particular social, economic and political context. They arise out of a social structure, they are grafted onto it, and they reinforce it or destroy it, often in ways that are neither foreseen or foreseeable" (49). The endoscope and its images have already begun to move past their original intentions and expert uses. Endoscopy is not only about the technical specifications of a technology but about the individuals and groups who use the technology to "construct and maintain" themselves, as Carolyn Marvin has written (197). And, according to Baudrillard, technology is neither simply a thing nor an object, it is part of the space we exist in, the space of "ephemeral connections" (130). We 
who use or take part in this technology and are also part of its essence can neither only be subjects, nor, in the case of endoscopic images, only exist as objects worked upon by doctors. The more we learn about the body via technologies, integrating their images into our own eye's vision and our interpretation of images, the more we begin to recognize the body as a construction, an assemblage of multiple selves emerging and existing in a "pattern of resonance and interference" (Halberstam and Livingston 10) between different systems, contexts, networks or "scapes" (Appadurai, 1994). The endoscope goes where the human eye cannot, but is still based on our human optics. It is inherently connected to our biology and our history/ knowledge of seeing as we explore "new" places with it and develop different perspectives on the body.

An example of the public accessibility of endoscopic images is the Given Imaging website (2005). This corporate site, aimed at selling this technology to practitioners, acknowledges patients' interests - it is not for experts' eyes only, and, as with anything on the internet or otherwise, each visitor has different reasons for accessing it. However, most "non-experts" don't know quite what they're looking at, and are not able to tell their esophagus from their pyloric opening let alone diagnose abnormalities. Yet the images are interpreted nonetheless, on an individual level.

Some of the images on givenimaging.com are from the "PillCam" - much like endoscopy in many ways but without the manual probing of the physician. The images the PillCam produces are similar to those of traditional endoscopy, but the $11 \mathrm{~mm}$ by $26 \mathrm{~mm}$ video capsule works with the body's own peristalsis, that is, the involuntary contraction of the digestive system. The 4-gram digital camera in pill form has a 140 degree field of view and generates approximately 57,000 images at a rate of 2 frames per second in the 8 hours it takes to pass through the body. These images are recorded onto a data recorder that is worn by the patient (statistics from Given Imaging, 2005). My first reactions to these images are to think about what they look like and remind me of or the narratives they inspire. 
We all have different reactions, but the question isn't just about what cultural influences affect our reactions, but about how we react in such culturally based ways. This technology and its medical-scientific intentions can't keep culture at bay. In looking at bodies that could be our own or someone else's, we can't separate these bodies into objects to be gazed at in one manner only, for example, that of pure biology or of diagnosis or illness. There are countless things - subjectivities, metaphors, spaces, and so on - surrounding these rhizomatically (Deleuze and Guatarri, 1987). Such a technology, especially when it produces such compelling images, cannot stay cloistered within the discourses of science and medicine. It leaks, as our bodies do, into and out of everything in life.

The high quality of the latest endoscopic images, with their brightness and digital detail, renders these images somehow more direct, closer perhaps to how our own eye would see them if looking directly inside the body. In many ways, are we not simply glad to be able to see these images, to be able to create and use technology to not only extend our eye but create an eye that sees in different ways and lends us perspective that we didn't have before? Certainly, these images are mediated even if the technology seems to aim to make that media more transparent. But the mediation remains, perhaps allowing us to retain some distance and even objectivity despite the intimacy of the content. If the body on screen is our own, the relationships between subject/object and objectivity/objectification are further broken down as one is forced to recognize images of the self that one has never seen before and collate them into our current self knowledge.

This sets us up to be able to explore the many subjectivities made possible through these images. The images not only tap into our ideas of narrative and metaphor, but into our experiences of health care and our own explorations of our bodies, visual or otherwise. We may squirm, become aware of what is going on inside us as we watch, think about the patient's body, and what the doctor is going to find or do with these images. This is not only a story being 
told to us or a film being shown to entertain, but these filmic images have obvious placements within culture, within our experiences. And they demand questions of us: Who are we now that we know we look like this, at least on the inside? What is our relationship to our physiology/biology? What is our relationship to the technologies that allow for these images? And to the "experts" who control them? Because even if they appear to control themselves, especially the PillCam, these technologies have still been manufactured by expert eyes and in the case of endoscopes, are moved by expert hands.

In an essay looking at the historical roots of dualist ideologies in science, Ruth Berman writes that the Cartesian positivist image of objectivity serves to establish distance and the authority of the observer over the observed. Berman writes: "The separateness of the power-wielders, the 'objective' ones, form the powerless, the 'objects', and the dominant social role of the former is also expressed by the numerous other polarities we are always being confronted with (e.g., mind-body, thinking-feeling, nature-nuture). These are all, in fact, rationalizations for usurping and exercising power" (237). The goals of the practitioners of science are derived from the social process in which they operate, argues Berman (230). We therefore require interdisciplinarity to address scientific and medical issues on multiple cultural/social levels that can scrutinize the ideologies of science.

\section{Making (more) surfaces visible}

The images brought to us via endoscopy are part of how we see ourselves and others, and emphasize the importance of visuality in culture, especially in medicine and science. When, for instance, we walk down the street, we might understand people not only for their faces and their hair but as their stomachs and colons, much more obviously wet and fleshy, just like ourselves. This explodes our understanding of surfaces - the places we judge others and ourselves and how we come to know them. This idea conjures Jameson's articulation of postmodernism as a "new depthlessness" in a "new culture 
of the image" (58). In this world, the body as material has meaning, and so does the social that the material exists in, being tied symbiotically. Content and surface, object and subject become each other. If we are "all surface," then we are not actually consciously "expressing" anything, we just express constantly - we are a part of our own and others texts, that is, and act within or through them. Endoscopy exposes our depthlessness, our previously unseen surfaces. Meaning that when something is hidden from view it is not necessarily "inside" something else as a "depth" - it is a surface yet to be revealed.

The body is a constructed thing - we can't take it as a biological given and must understand that it changes with us and with our changing culture/environment. Its surfaces exist in the world, touch it and are touched by it, and are both acted upon and act themselves. They are not the standardized images of medical anatomy one would find in a book or in a medical school, but much like our skin, eyes and lips, the inside of the body shares similar traits with other humans' insides, but still differs greatly too. As Deborah Lupton states, increasingly, as we understand the body as part of social theory, "the body is not seen as universal biological realities but as a combination of discursive processes, practices and physical matter, which have a symbiotic and symbolic relationship within society" (49)

Biologist Lynda Birke writes about how the body should be understood as organs and physiological processes, while at the same time acknowledging needs to visualize the body, and thereby know it through representations developed within our culture (through such forms as scientific diagrams, the endoscopic gaze, body scans, art and the media). Yet when such things are made visible, what is done with the information gained from that perspective? What is visible or visual is not necessarily the truth or the answer to what we're looking for, but only part of a larger puzzle. For example, seeing abnormalities in the intestine is not the answer to disease, but a way towards the answer - we become aware that something is wrong, can pinpoint its place, but now we have to figure out how to go about 
fixing it as part of the larger, non-static, partially culturally-defined body it exists within. The visible is part of the broader conversation, as Foucault has argued - we are able to talk about these images, theorize them, and integrate them further into our environment.

Gilles Deleuze writes about the need for a non-human eye, an eye between and inside things. He is talking about cinema, but also how parts are linked together in many ways, forming an open whole that changes as its parts link while being clearly separate as well (qtd. in Boundas, 1993). Any point on a rhizome can be connected to any other point, from the physical body to the wider sociocultural realm. "There is no unity to serve as a pivot in the object or 'return' to the subject" (Deleuze and Guatarri 30) - the subject and object in this case are one in the same; one looks at oneself while being oneself. Why have a distinct "inside" when you are both inside and outside at the same time via the rhizomatic multiplicity of the system you're in at that moment - in this case, the moment of looking at the endoscopic image, especially when these images could be representative of your own body.

Rather than subjects or objects or subject-objects, we could be implicated witnesses. Donna Haraway writes in Modest Witness@Second Millennium. FemaleMan@_Meets_OncoMouse ${ }^{\mathrm{TM}}$ that in keeping with the commitment to "cyborg articulations," that "valid witness depends not only on modesty but also on nurturing and acknowledging alliances with a lively array of others, who are like and unlike, human and not, inside and outside what have been the defended boundaries of hegemonic selves and powerful places" (269). There is culture in science and science in culture, nature in the technoscientific and vice versa. She insists that ours is a time of implosion of nature and culture; we witness this implosion from our multiple locations and see it explode as well. The endoscope and its digital images as they stand now are a site of implosion; when we witness them as part of culture, they explode as part of the world, and dualisms can't be adhered to. 
In some ways, cyborg theory is all about the body and the body's presence and articulation, while in other ways cyborg theory is highly abstract; it is about simultaneously looking, being looked at, and being able to see oneself in one's environment from within the same body. It is a way of acknowledging, and in fact embodying, the end of subject-object relations in a visceral way - Haraway describes the cyborg as "a disassociated and reassembled post-modern collective and personal self" ("A Cyborg Manifesto" 163). I align this self with the connections felt when looking at endoscopic images; being human is more of an abstraction than a definition. It encompasses so much and is defined in so many different culturally-dependent ways. We keep entering new phases of being human, adjusting our understanding of what it means to be human in a particular time and place, as new technologies and our examination of them make the many, possibly innumerable, surfaces or sides of ourselves more clear and more widely accessible.

\section{Works Cited}

Appadurai, Arjun. "Disjuncture and Difference in the Global Cultural

Economy." Colonial Discourse and Post-colonial Theory. Ed. P. Williams and

L. Chrisman. New York: Columbia UP, 1994. 324-339.

Baudrillard, Jean. "The Ecstasy of Communication." The Anti-Aesthetic: Essays on Postmodern Culture. Ed. Hal Foster. Port Townsend, WA: Bay Press, 1983. 126-134.

Berman, Ruth. "From Aristotle's Dualism to Materialist Dialectics:Feminist Transformation of Science and Society." Gender/Body/Knowledge: Feminist Reconstructions of Being and Knowing. Ed. Alison M. Jaggar and Susan R. Bordo. New Brunswick, N.J.: Rutgers UP, 1989. 224-255.

Birke, Lynda. Feminism and the Biological Body. Edinburgh: Edinburgh UP, 1999.

Boundas, Constantin V., ed. The Deleuze Reader. New York: Columbia UP, 1993.

Deleuze, Gilles and Guattari, Felix. A Thousand Plateaus: Capitalism and

Schizophrenia. Minneapolis, MN: U of Minnesota P, 1987. 
Franklin, Ursula. The Real World of Technology. Concord, Ont.: Anansi, 1990.

Given Imaging. Jan. 2005. <http://www.givenimaging.com>

Halberstam, Judith and Livingston, Ira, eds. Posthuman Bodies. Bloomington and Indianapolis: Indiana UP, 1995.

Haraway, Donna. Modest Witness@Second Millennium.Female-Man@__Meets_ OncoMouse ${ }^{\mathrm{TM}}$ : Feminism and Technoscience. New York: Routledge, 1997.

---. "A Cyborg Manifesto: Science, Technology, and Socialist-Feminism in the Late Twentieth Century." Simians, Cyborgs and Women: The Reinvention of Nature. NewYork: Routledge, 1991. 149-181.

Heidegger, Martin. "The Question Concerning Technology.” The Question Concerning Technology and Other Essays. NewYork: Harper \& Row, 1977. 3-35.

Jameson, Fredric. "Postmodernism, or the Logic of Late Capitalism." New Left Review 145 (1984): 53-92.

Lupton, Deborah. Medicine and Culture: Illness, Disease and the Body in Western Societies. London: Sage Pubications, 1994.

Marvin, Carolyn. "Experts, Black Boxes, and Artifacts: New Allegories for the History of Electronic Media." RethinkingCommunication. Vol. 2. Ed. B. Dervin, L. Grossberg, L.O'Keefe, and E. Wartella. Newbury Park, CA: Sage, 1989.188-198.

Van Dijck, José. “Bodies without Borders: The Endoscopic Gaze.” International Journal of Cultural Studies 4.2 (2001): 219-237. 